\title{
A Study on Model Development of Liberal Arts College through American Liberal Arts Colleges
}

\author{
Yoon-cheol Park ${ }^{1)}$ \\ 미국의 리버럴 아츠 칼리지를 통한 교양 대학 모델 개발 \\ 연구
}

박윤철1)

\begin{abstract}
The purpose of this research is to examine and propose the new model of liberal arts colleges in Korea. The educational system and curriculum of Korean liberal arts colleges have imitated the model of the U.S. and primarily provided educational programs for freshmen. It shows that liberal arts colleges had interest in the basic knowledge of majors, but not in independence and autonomy. This educational system ultimately leads students to be unsatisfactory in the educational services. For solving the problem, the new model of liberal arts college presented in this research offers educational systems such as four-year academic system, separate curriculum from majors, and educational programs for basic knowledge, culture, and attainments. The model will help students have self-esteem and general knowledge as a member of society after graduation and give opportunities to experience various studies such as literature, arts, philosophy, science, and physical education, etc. Accordingly, the new model of liberal arts colleges proposes the need to establish separate education system and curricula for fostering creative talents.
\end{abstract}

Keywords: Curriculum, General Education, Korea Education, Liberal Arts, Vocation Education

\section{요 약}

지금까지 국내에 있는 교양 대학들은 미국의 리버럴 아츠 칼리지를 모방하여 기초, 교양, 전공 기초 에 비중을 두고 대학교 1학년생을 대상으로 교육 프로그램을 전개해 왔다. 하지만 미국 리버럴 아츠 칼리지의 교육 과정과 달리 국내 대부분의 교양 대학들은 직업 교육과 연관된 교과 프로그램을 제공 하였을 뿐만 아니라 독자적인 학사 구조를 구축하지 못한 한계성을 띠고 있었다. 따라서 본 연구는 미국의 리버럴 아츠 칼리지를 통한 새로운 교양 대학 모델을 제안하는 데 그 목적을 두고 있다. 본 연구에서 분석한 새로운 교양 대학의 모델은 미국 리버럴 아츠 칼리지의 4년제 교육시스템, 독립된

Received(June 9, 2020), Review Result(1st: July 31, 2020, 2nd: September 19, 2020), Accepted(October 28, 2020)

1) (Professor) 51767 Dept. of English Education, Kyungnam Univ., Wolyoung-dong, Masanhappo-gu, Changwon, Gyeongsangnam-do, Korea

email: lingular@hanmail.net 
학사 구조, 기초, 교양, 소양 교육 프로그램을 포함하는 교육 과정을 제시하고 있다. 이러한 교양 대 학 모델은 전공 교육처럼 긴 시간에 걸쳐 문학, 예술, 철학, 과학, 체육 등 여러 학문을 통섭하여 문 화인으로서 자유인으로서 사회생활을 유지하는데 품위와 지식을 배양할 수 있는 교육 체계를 말한다. 무엇보다 새로운 교양 대학의 모델은 단순히 전공 교육의 기초 교육에서 벗어나 창의적인 인재를 배 출하기 위한 교육 기관으로서 독자적인 교육 프로그램과 교육 과정 확립의 필요성을 제안하고 있다.

핵심어: 교과 과정, 교양 대학, 한국 교육, 리버럴 아츠, 직업 교육

\section{1. 서론}

오늘날 대학의 교양 교육은 '대학 속에 대학'이라고 불릴 만큼 교수들과 대학 관계자들이 4 차 산업 혁명 시대를 대비한 교육 개편과 강화에 많은 관심을 두고 있다. 과거와 달리 대학 내에서 교양 과목을 담당하는 기관도 교양 기초 교육원이나 교양 학부에서 교양 대학으로 격상하는 추세는 교 양 교육이 변두리 위치에서 학부 교육의 중심축으로 이동하고 있음을 증명한다. 이처럼 교양 대학 의 격상은 다행스러운 일이기도 하며 한국 사회의 정치적, 경제적, 교육적 흐름을 반영한 결과의 산물이라고 볼 수 있다.

사실 한국의 교양 교육은 처음부터 자생적으로 발전하지 못하고 미국 교육 체계로부터 영향을 받아 왔다. 그리고 국내 대학에 설립된 교양 대학의 대부분은 미국의 리버럴 아츠 칼리지(Liberal Arts College)의 시스템과 교과 과정을 모방한 측면이 강하다. 그러나 미국의 리버럴 아츠 칼리지 와 한국의 교양 대학 체제는 교육 환경이나 교육 제도 등에서 차이점을 갖고 있다. 예를 들어 미 국의 리버럴 아츠 칼리지는 기초 교양과 전공 교육을 합친 중앙 집중형 또는 학제 간 융합성을 강 조한 교육 체계를 제공하고 있다면 국내의 교양 대학들은 기초와 교양 또는 기초, 교양, 전공 기초 를 합친 형태의 교육 과정을 제시하고 있다. 이러한 차이는 각 대학별 특성을 고려한 교육 과정을 보여주며 국내 대학들이 보편적으로 지향해야 할 교육 체계의 방안을 필요로 하는 모습을 보여준다.

따라서 본 연구는 미국의 리버럴 아츠 칼리지를 통한 새로운 교양 대학 모델을 제안하는 데 그 목적을 두고 있다. 이러한 연구 목적의 배경은 교양 대학이 전공 연계로부터 탈피한 학사 구조, 교 육 프로그램, 교과 과정을 갖춘 교육 체계에 대한 선행 연구가 부재하다는 사실에서 비롯된다. 그 러므로 본 연구에서 추구하는 교양 대학의 모델은 미국의 리버럴 아츠 칼리지를 기반으로 하고 있 지만 한국 교육 문화와 지역 대학에 적합한 모델을 모색하는 데 의의를 두고 있다. 따라서 본 연 구에서 제시하는 새로운 교양 대학의 모델은 교양 교육 체계의 일관성을 확립하는데 기여할 것으 로 기대된다.

\section{2. 국내 교양 대학의 문제점과 연구 동향}

\section{1 국내 교양 대학의 문제점}

지금까지 교양 대학들은 각각 특성화된 기초 교육에 비중을 두고 있었다. 그러나 4 차 산업혁명 시 
대를 맞이하는 시점에서 교양 대학의 교육 프로그램들은 기존의 틀을 통해 양질의 교육 서비스를 제공하는 데 한계성을 지니고 있다. 이러한 교육 경향을 반영하듯 최근 일부 대학에서 리버럴 아 츠 칼리지의 설립은 고무적인 일이며 앞으로 교양 교육이 합리적인 사고를 지닌 교양인을 양성하 는데 어떠한 교육 접근과 방향을 설정해야 하는지를 잘 보여준다. 그러나 현실적으로 국내 대학에 있는 대부분의 교양 대학들은 리버럴 아츠 칼리지의 교과 프로그램을 일부 혼합시킨 형태로 그 정 체성을 찾아보기 힘들며 다음과 같은 문제점을 안고 있다.

문제점: 국내의 교양 대학과 미국의 리버럴 아츠 칼리지는 교육 환경과 교육 제도 측면에서 많 은 차이점을 갖고 있다. 이러한 점에서 국내의 교양 대학들은 학과 및 전공 중심의 학사 구조에서 벗어난 독립 기관으로서 한국 문화와 교육 현실에 맞는 교육 체제를 구축할 수 있는가?

위의 문제점을 언급하기에 앞서 미국의 리버럴 아츠 칼리지는 인문학, 사회 과학, 자연 과학, 어 학 등 교양 과목에 중점을 둔 학부 중심의 4년제 대학으로 구성되어 있다. 이에 비해 국내 교양 대학들은 종합 대학 내에서 주로 1 학년을 대상으로 계열 기초, 공통 교양, 일반 교양으로 구분하여 전공과 연계된 기초 학문에 중점을 두고 있다. 이러한 교과 과정은 교양 교육 본래의 취지인 인문 학적 소양을 갖춘 창의적 인재를 양성하는 데 한계성을 지닌다. 다시 말해 국내의 교양 교육은 전 공 학문의 기초 실력 배양에 중점을 두고 있기 때문에 올바른 교양 교육이 실현될지 의구심을 지 니게 만든다.

사실 교양 교육은 전공 교육처럼 긴 시간에 걸쳐 철학, 문학, 예술, 과학, 체육 등 여러 학문을 답습하는 과정을 통해 교양인으로서 소양을 갖춘 인재를 양성할 수 있다. 그럼에도 불구하고 현재 국내 대학들은 대학 1 학년에 한정시켜 전공 기반의 계열 기초 학문을 제공하는 교육 프로그램을 통해 합리적이고 이성적인 사회인을 양성하는 데 어려움을 갖고 있다. 그러므로 국내 교양 대학의 모습은 현재와 다른 순수 교양 학문을 위한 교육 과정과 교육 체계 및 교육 프로그램들이 요구된 다. 그러면 이러한 국내 교양 대학들에 관한 기존의 연구들은 어떠하였는지를 다음 절에서 살펴보 겠다.

\section{2 교양 대학에 대한 선행 연구 동향}

현재까지 국내의 교양 대학 모델에 관한 연구는 미미한 수준에 머무르고 있으며 주로 교양 교육 또는 기초 교육에 집중되는 경향을 띠고 있다. 그러므로 교양 대학과 관련된 연구보다 교양 교육 을 중심으로 손동현(2016)[1], 최병문(2016)[2], 백승수(2016)[3], 안현호(2016)[4] 등이 학과 중심의 학 부 교육에 대한 대처, 인문학의 위기를 극복하기 위한 대책, 교양 교육의 활성화와 같은 내용으로 연구되어 왔다. 이러한 연구들은 기존의 교양 기초 교육원이나 교양 대학이 추구하고 있는 교육 과정의 현실을 보여주며 학과 중심으로부터 보조적 역할에 불과하다는 비판과 함께 그 개선 방안 
을 제시하고 있다.

한편 리버럴 아츠 칼리지에 관한 해외 연구 동향은 Backer(2016)[5], Cech(1998)[6], Janeksela(2016)[7] 등 교양 교육과 직업 교육 간의 경계를 어떻게 구분할 것인가에 대한 비판과 새로운 교과 과정 개 발 방안을 제시하는 연구에 집중되어 있다. 이러한 연구 동향은 교양 교육에 대한 교육 체계 및 교과 과정에 대해 서양이 국내보다 더 많은 고민과 방안을 찾으려는 의도로 해석된다.

그리고 외국 연구의 주요 관심사는 21 세기 인재상을 준비하기 위한 리버럴 아츠 칼리지의 운영 과정과 교과목 개발 혹은 사회 변화를 반영한 새로운 교과목의 적용 등 여러 변수들을 전제로 교 과 과정에 비중을 두는 경향으로 나타난다. 이러한 점에서 교양 교육과 직업 교육 간의 갈등으로 인한 교육 과정 개편 또는 학제 개편에 대한 연구들은 국내를 포함하여 외국에서도 해결해야 할 과제로 고려된다.

이와 같이 교양 대학에 관한 국내외 연구들은 교양 교육을 중심으로 직업 교육과 교양 교육 사 이에 직면하고 있는 사회적, 교육적 문제를 해결하기 위한 방안으로서 제시되고 있다. 이것은 4 차 산업혁명 시대를 대비한 인재를 양성하기 위한 교두보 역할로서 새로운 형태의 교양 대학을 정립 하고 재구성하려는 의도를 내포한다. 그러므로 새로운 교양 대학 모델 개발은 기존의 기초 및 교 양 교육에 더욱 활기를 불어 넣어 앞에서 언급한 문제를 해결할 수 있는 대안으로서 작용할 것이 다. 그러면 다음 절에서 새로운 교양 대학 모델 개발을 위한 미국의 리버럴 아츠 칼리지에 대해 좀 더 구체적으로 살펴보기로 하겠다.

\section{3. 미국의 리버럴 아츠 칼리지를 통한 교양 대학 모델}

\section{1 미국의 리버럴 아츠 칼리지}

근래 많은 사람들이 사용하고 있는 리버럴 아츠 칼리지라는 용어는 영어로 Liberal Arts College이 며 교양 대학과 구분하여 사용되고 있다. 리버럴 아츠(liberal arts)는 고대 그리스에서 내려오는 자 유롭고 폭넓은 학문 수양을 뜻한다. 그러므로 리버럴 아츠 칼리지는 역사학, 문학, 철학, 미학 등과 같은 인문학 그리고 경제학, 사회학, 정치학 등의 사회 과학을 포함하여 수학, 물리학, 화학, 생물 학과 같은 순수 과학에 걸쳐 폭넓은 지식과 교양을 쌓기 위해 많은 양의 독서와 작문, 토론의 기 회를 통해 비판적 사고와 창의성을 함양함으로써 학문적 토대를 완성하는 것을 추구한다. 그리고 리버럴 아츠에 관한 개념은 아래처럼 사전에 정의되고 있다.

리버럴 아츠(Liberal Arts): 고대 라틴어 '아르테스 리베랄레스(Artes Liberales)'에서 유래한 말로 자유 시민을 위한 학문을 뜻한다[8].

위의 정의처럼 리버럴 아츠는 다양한 분야의 지식을 습득하여 사고의 틀을 깨는 것이 리버럴 
아츠의 목적이다. 고대 그리스 로마 시대에 리버럴 아츠는 문법, 변증법, 수사학, 산술, 음악, 천문, 기하학과 같은 일곱 학문에 핵심을 두고 있었기 때문에 '자유 칠과(Seven Liberal Arts)'라고도 불 렀다. 또한 일곱 영역의 리버럴 아츠는 중세 대학의 커리큘럼이었고 중세 시대의 귀족 계급들은 이러한 학문을 배웠지만 그 이하의 계급들은 전문적이고 직업 교육을 위한 실용적 기술 교육을 수 학하였다. 그러므로 리버럴 아츠는 자유 시민으로서 갖추어야 할 기본 교양을 쌓기 위한 교육에 해당된다.

한편 미국의 리버럴 아츠 칼리지 형태는 연구 중심의 종합 대학과 대비되는 개념으로 학부 중 심 대학이며 학위 수여의 절반 이상이 인문학과 과학 분야에서 학생들이 배출되지만 최근에는 공 학 학위를 수여하는 리버럴 아츠 칼리지도 있고 심지어 몇몇 리버럴 아츠 칼리지는 경영학, 간호 학, 교육학, 법학, 의학, 약학 분야의 대학원을 운영하며 석·박사 학위 과정을 제공하는 교육 과정 을 확대하고 있다.

그리고 리버럴 아츠 칼리지의 주요한 특징은 교양 교과 과정이 주요 커리큘럼으로서 학생 수가 3,000 명 이하가 될 정도로 적고 주거형 학교로서 학생과 교직원들의 커뮤니티가 돈독하며 학생 대 비 교수의 비율이 높다. 또한 교과목에 대한 수강생의 밀도가 낮은 편으로 교수와 토론 수업 등 밀착 학습이 가능하며 교수들이 연구보다 강의에 집중하는 연구 중심의 종합 대학들과 대조를 이 룬다. 리버럴 아츠 칼리지는 글자 그대로 '가르치는 대학'의 위상을 표방하고 있기 때문에 자유로 운 학문 탐구와 일관된 교육 프로그램의 실행을 추구한다. 하지만 리버럴 아츠 칼리지는 직업 교 육과 관련된 응용과학이나 공과 계열의 교과목을 제공하지 않기 때문에 어떤 측면에서는 '인문과 순수 과학 대학이라 부른다.

그러므로 미국의 리버럴 아츠 칼리지에 다닌 학생들은 졸업 후 취업과 관련하여 대학원을 진학 하거나 전문 직업을 얻기 위해 별도의 직업 훈련 과정을 필요로 한다. 이것은 국내 대학들의 현실 에 적합하지 않는 측면을 보여준다. 왜냐하면 국내 대부분의 대학들이 대학 평가 지표 가운데 하 나인 취업률에 낮은 결과를 초래하기 때문이다. 따라서 국내 교양 대학들이 미국의 리버럴 아츠 칼리지 형태를 유지하면서 한국 교육의 현실을 감안한 교과 과정을 어떠한 형태로 구성해야 할지 그리고 취업률과 연계된 교과 과정 및 학제 편성을 어떠한 방식으로 구축해야 할지를 살펴볼 필요 성이 요구된다.

사실 교양 교육을 강조하고 있는 리버럴 아츠 칼리지는 유럽에서 유래하였지만 현재 전 세계의 많은 나라들이 그 나름대로의 교육 문화와 교육 체계에 맞게 품격 있는 교육 프로그램을 제공하고 있다. 앞에서도 언급하였듯이 리버럴 아츠 칼리지는 주로 미국 북동부 지역에 있는 학부 중심 대 학이며 다른 나라의 리버럴 아츠 칼리지보다 더욱 발달된 학사 구조와 교과 과정을 편성하고 있 다. 미국의 리버럴 아츠 칼리지에 다니는 학생들은 보통 3 4년간 기본적인 학문을 수학한 다음 대 학원이나 의대, 법대, 경영대로 진학하여 졸업 후 취업하는 방법을 택하고 있다. 예를 들어 어떤 학생이 리버럴 아츠 칼리지에 다니면서 엔지니어링 공부를 하고 싶다면 처음 3년간은 기초 학문을 학습한 후 다른 종합 대학의 공과 대학에 2 년간 더 공부하면 된다. 결국 이 학생은 5 년 후에 리버 
럴 아츠 칼리지에서 학사 학위를 받고 엔지니어링 학위도 받게 된다[9]. 이러한 방식의 교육 프로 그램은 한국 사회의 현실에 수긍할 만한 교육 체계로 간주된다. 그러면 국내 일부 대학에서 실행 하고 있는 리버럴 아츠 칼리지는 어떠하였는지를 다음 절에서 살펴보자.

\section{2 국내 리버럴 아츠 칼리지}

국내 A 대학은 종합 대학 내에서 리버럴 아츠 칼리지를 두고 있으며 기초 학문 중심으로 교양 교 육을 진행하고 있다. 또한 $\mathrm{A}$ 대학의 리버럴 아츠 칼리지는 교양과 전공을 융합한 교과목도 개설하 여 창의적 인재 육성을 목표로 하고 있다. 한편 국내 B 대학은 기초 학문 분야를 토대로 응용 학 문을 공부할 수 있는 교육 프로그램을 제시하고 있으며 기숙 형태를 통해 학생과 연대감을 높이는 교육 체제를 구축하기 위해 노력하고 있다. 국내 C 대학은 기존의 교양 대학에서 확대 편성된 형 태로 교양 기초 과목을 중심으로 계열 기초, 융합 기초, 일반 선택 교과목을 편성하여 내실화를 추 구하고 있다. 하지만 이러한 대학들은 B 대학을 제외하고 기존의 교양 교육 프로그램의 틀을 벗어 나지 못한 형태를 취하고 있으며 학과 및 전공 중심으로부터 독립된 교육 체제를 구축하지 못한 한계점을 드러내고 있다.

좀 더 구체적으로 언급하면 A 대학은 순수 자유 학문으로서 기능을 표방하고 있지만 취업을 염 두에 둔 직업 교육과 연관성을 지니고 있는 문제점과 B 대학은 리버럴 아츠 칼리지가 갖추어야 할 교육 프로그램 이외에도 직업 교육과 관련성이 높은 학과 배치는 리버럴 아츠 칼리지가 지닌 본래의 취지를 희석시키는 결과를 초래한다. 마지막으로 C 대학은 표면적으로 리버럴 아츠 칼리지 를 추구하고 있지만 실질 교과 과정이나 교육 체제는 기존의 교양 기초 교육원 혹은 교양 학부에 서 시행한 교과 과정을 그대로 유지하고 있는 문제점을 지적할 수 있다. 이것은 미국의 리버럴 아 츠 칼리지를 모방한 교양 교육보다 한국 교육 문화에 부합하는 교양 대학 모델의 개발이 요구되며 또한 내실화된 교육 체제와 형태가 무엇인지를 고민하게 만드는 결과를 초래하고 있다.

사실 미국의 리버럴 아츠 칼리지들이 추구하는 교육 이념은 수학과 자연 과학, 전통 인문학, 사 회학을 대상으로 광범위한 학문 주제를 다룸으로써 세계인으로서 인류에 대한 헌신과 도덕적 책무 를 실천하려는 인재로 거듭나는 데 있다. 이에 반해 국내에 리버럴 아츠 칼리지를 갖고 있는 대학 의 교육 이념은 약간의 차이를 두고 있지만 창조적, 비판적 사고를 지니면서 문제 해결 및 의사소 통 능력을 갖춘 인재를 육성하는 데 비중을 두고 있다. 이러한 교육 이념은 교과 과정의 학사 제 도를 어떻게 편성해야 할지를 명확히 제시한다.

특히 전공과 학과 중심에서 벗어난 교양 교육 프로그램의 요구는 4 차 산업혁명 시대를 준비하 는 대학들에 또 다른 과제로 다가온다. 대부분의 대학들은 학과의 담을 무너뜨리고 융복합 모델을 구축하여 창의적, 창조적 인재 양성을 목표로 하고 있지만 과연 이러한 교육 모델들이 교양 교육 의 본래 취지와 부합되는지 의구심을 가지게 만든다. 다시 말해 해외의 교양 교육은 자유인으로서 문제 해결 능력을 갖추고 자율적이고 비판적 시각으로 대상을 살펴볼 수 있는 안목을 넓히는 데 
역점을 두고 있다면 국내 교양 교육은 취업 및 학과의 편제 수준에 지나지 않는 형태로 진행되고 있다. 이것은 국내 종합 대학 내에 있는 교양 대학이 독립된 기구로서 자유 학문 또는 교양 교육 을 실현시킬 수 있는 학사 제도와 교육 과정에 대한 기준이 무엇인지를 모색하는 기회를 제공한 다. 그러면 다음 절에서 이러한 교양 교육의 기준과 모델에 대해서 살펴보자.

\section{3 국내 교양 교육의 표준과 모델}

국내에 있는 종합 대학들은 기초 교육 프로그램을 편성할 때 대체로 거의 비슷한 기초 교육의 교 과목과 학사 제도를 공유하고 있지만 소양 교육에 있어 약간의 차이를 나타낸다. 한국 교양 기초 교육원에서는 교양 교육을 기초 교육, 교양 교육, 소양 교육으로 구성하여 체계적으로 제시하고 있 다. 아래는 한국 교양 기초 교육원(2019)[10]에서 제시하는 「교양 교육 표준안」의 각 영역별 교육 과정 내용을 나타낸다.

기초 교육: 대학 교육을 받기 위한 기초 지식 및 기본적인 지적 언어적 능력을 함양하는 교육을 가리킨다. 여기에는 탐구의 대상을 분석 이해하고 문제를 찾아내며 비판적, 창의적 사고를 통해 문 제를 해결하려는 지적 시도를 하여 그 결과를 다시 다양한 언어적 매체로 표현함으로써 다른 사유 주체와 원활한 의사소통을 할 뿐만 아니라 자신의 견해를 다른 사람이 수용하도록 설득하는 지적 언어적 훈련이 포함된다.

교양 교육: 교양, 기초 교육 과정의 본령이다. 인간, 사회, 자연에 대한 학문적 탐구 성과를 두루 습득함으로써 이 주제 영역에서 제기되는 여러 근본 문제에 대한 이해를 갖고 이를 토대로 나름대 로 그에 대한 식견을 갖는 교육이다. 외부의 객관적 세계에 대한 일관된 체계적 총괄적 견해인 세 계관, 그 세계 속에서 삶을 영위하는 자신을 포함한 인간 존재에 대한 균형 잡힌 총괄적 견해인 인간관, 주어진 세계를 넘어 실천을 통해 실현되어야 할 가치와 당위의 세계에 대한 일관된 견해 인 가치관이 그 식견의 주요 내용을 이룬다.

소양 교육: 교양 교육을 비롯해 대학에서 학문 탐구의 궁극 목적이 되기도 하고 그 전제가 되기 도 하는 포괄적 의미에서 '인성’을 함양하는 교육을 가리키는 것으로 이 용어를 사용해 본다... 지 성인이 되기 위해 대학생들이 지녀야 할 소양에는 미적 감수성으로 나타나는 정서적 자질과 공동 체적 삶을 가능케 하는 인애(仁愛), 정의, 배려, 정직 등의 도덕성이 핵심인 것으로 자리한다... 따 라서 이 영역의 교양 교육, 즉 '소양 교육'은 부분적으로 정규 수업에서 다루어진다 해도 비정규 프로그램과 연동하여 이루어지는 것이 바람직하다.

위에서 언급하고 있듯이 교양 교육은 크게 기초, 교양, 소양 교육 영역을 중심으로 구성되어 있 다. 각 영역에서 제시하고 있는 교양 교육의 내용은 대학생으로서 사회인으로서 자유인으로서 참 된 인재상을 양성할 것을 목표로 한다[11]. 그러므로 각 영역에 포함된 교과목과 학점 부여는 형평 
성과 균형을 요구한다. 왜냐하면 어느 한 영역에 치우친 교육 과정의 편성은 올바른 인재를 배출 하기 어렵기 때문이다. 그러므로 각 대학별 학사 제도는 불균형적 학점 부여 또는 특화라는 이유 로 비대칭적 구조의 학사 운영을 피하고 균형 잡힌 학사 운영을 수행할 필요성을 가진다.

사실 이상적인 교양 대학 모델은 학습 내용을 단순히 외우면서 공부하는 것이 아니라 폭넓은 교양 과목의 수강을 통해 사고 능력과 표현 능력을 배양하는데 주안점을 두고 있다. 또한 교양 대 학의 교육 방향은 어느 한 영역에 치우친 사고를 가진 인재를 배출하는 것이 아니라 통섭적 인간 을 양성하기 위한 교육을 실현시키는 교육 프로그램을 제공해야 한다. 따라서 아래와 같은 교양 대학의 모델이 대안이 될 수 있다.

교양 대학 모델

$$
\text { 교양 모델 }=>\left[\begin{array}{l}
4 \text { 년제 교육시스템 } \\
\text { 독립된 학사 구조 } \\
\text { 기초, 교양, 소양 프로그램 }
\end{array}\right.
$$

위의 모델에서 볼 수 있듯이 교양 대학의 모델은 미국 리버벌아츠 칼리지의 4 년제 교육시스템 을 바탕으로 독립된 학사 구조를 통해 기초, 교양, 소양 교육 프로그램을 제공하는 대학의 면모를 갖추고 있다. 위의 교양 대학 모델은 기존의 교양 교육원이나 교양 기초 교육원의 교육 체계와 유 사한 체제를 가질 수 있지만 실질적으로 4년간 교육 프로그램이 제공된다는 측면과 문학, 예술, 철 학, 역사, 언어, 과학, 수학, 경제, 통계, 정보통신 등 기초, 교양, 소양 영역의 학문을 포함하고 있 다는 측면에서 차별성을 가진다. 게다가 위의 모델은 직업 교육보다 사회인으로서 지녀야 할 교양 과 소양 교육에 중점을 두고 있어 심도 있는 교육 서비스를 제공할 수 있는 측면에서 유리한 점을 확보한다. 특히 기존의 교양 교육이 주로 대학 1학년을 대상으로 제공하였다면 위의 교양 대학 모 델은 4 년 동안 전체 학생들에게 기초, 교양, 소양 영역의 교육 프로그램을 제시하고 있어 기존의 교양 대학들과 다른 면모를 찾을 수 있다.

지금까지 교양 교육은 짧은 기간에 한정된 교과목을 다룸으로써 폭넓은 지식을 배양할 수 있는 기회가 적은 것은 사실이다. 또한 교육의 질적인 측면에서도 전공과 비교하여 다소 불만족스러운 교과 운영을 진행해 온 것도 안타까운 현실이다. 하지만 교양 교육이 추구하는 인재상을 고려해 볼 때 위의 교양 대학 모델은 특정 영역의 학문에 치중된 것이 아니라 음악에서부터 철학에 이르 기까지 다양한 학문의 지평을 제공함으로써 통섭적 인재를 양성할 수 있는 기회를 제공한다.

사실 교양 교육은 고대 그리스 시대부터 학문에 대한 인간의 욕망을 충족시켜주는 기능을 수행 해 왔다. 또한 교양 교육은 시대적, 지역적, 문화적 특색을 반영하여 각 나라마다 여러 형태로 발 전되어 왔고 다양한 교육 제도를 갖추고 있다. 그러나 무엇보다 4 차 산업혁명 시대의 도래와 함께 교양 교육의 인재를 육성하고 적절한 교육 정책을 펼치기 위해서는 전문화된 교양 대학 기관의 확 립과 직업 교육과 분리된 자율적 교육 제도의 운용이 뒷받침되어야 할 것이다. 


\section{4. 결론}

오늘날 국내 교양 대학들은 4 차 산업혁명을 맞이하는 시점에서 미국 리버럴 아츠 칼리지의 모델을 기반으로 기초, 교양, 전공 기초에 역점을 두고 대학 1 학년을 대상으로 교육 프로그램을 전개해 왔 다. 하지만 이러한 국내 교양 대학들은 미국 리버럴 아츠 칼리지의 교육 과정과 달리 직업 교육과 연관된 교과 과정을 제공하여 그 한계성을 띠고 있었다.

본 연구는 이러한 현실을 감안하여 미국의 리버럴 아츠 칼리지를 통해 교양 대학의 새로운 모 델을 탐색하고 고찰하는 데 목적을 두고 있다. 국내 교양 대학들은 주로 학과와 전공 기초 지식을 배양하는 데 중점을 두고 있고 독자적 학사 편제나 자율성을 보장받지 못하고 있다. 결국 이러한 교육 체계는 학생들로부터 만족스럽지 못한 교육 서비스를 제공하는 문제점을 보여준다. 그러므로 본 연구에서 제시한 새로운 교양 대학의 모델은 미국 리버럴 아츠 칼리지의 4 년제 교육시스템, 독 립된 학사 구조, 기초, 교양, 소양 교육 프로그램이라는 교육 체계를 제안하고 있다.

이러한 새로운 교양 대학 모델은 전공 교육처럼 긴 시간에 걸쳐 문학, 예술, 철학, 과학, 체육 등 여러 학문을 통해 문화인으로서 자유인으로서 사회생활을 유지하는데 품위와 지식을 배양할 수 있는 교육 과정이라고 할 수 있다. 무엇보다 교양 대학은 단순히 전공 교육의 기초 교육에서 벗어 나 통섭적이고 창의적인 인재를 배출하기 위한 과정으로서 독자적인 교육 프로그램과 교육 체계의 확립이 요구된다.

\section{Acknowledgement}

이 연구결과물은 2019년도 경남대학교 학술 진흥 연구비 지원에 의한 것임

\section{References}

[1] Donghyun Son, Liberal Arts Education: New Horizon of Korea University Education, Proceedings of Spring National Conference 2016, (2016) Jun 24; Seoul, Korea.

[2] Byungmun Choi, Curriculum Development \& Operation of Liberal Arts, Proceedings of Spring National Conference 2016, (2016) Jun 24; Seoul, Korea.

[3] Sungsu Baek, Planning of Gachon University, Proceedings of Spring National Conference 2016, (2016) Jun 24; Seoul, Korea

[4] Hyunho An, Vitalizing Humanities through General Education, Journal of General Education, (2016), Vol.10, No.2, pp.131-155. 
[5] J. Becker, Liberal Arts and Sciences Education: Responding to the Challenges of the XXIst Century, Educational Studies, (2015), No.4, pp.33-61, DOI: 10.17323/1814-9545-2015-4-33-61

[6] T. R. Cech, Science at Liberal Arts Colleges: A Better Education?, Daedalus, (1999), Vol.128, No.1, pp.195-216.

[7] G. M. Janeksela, The Value of a Liberal Arts Education, Academic Exchange Quarterly, (2012), Vol.16, No.4, pp.37-41.

[8] Daum Encyclopedia, Liberal Arts, http://100.daum.net/encyclopedia/view/47XXXXXXd855, Jan 26 (2019)

[9] The Hankook Ilbo, Successful Life and Education of Children, http://ny.koreatimes.com/article/20040418/17426 4, Apr 19 (2004)

[10] Korea National Institute for General Education, The Standard for General Education, http://www.konige.kr/ sub02_08.php, Feb 1 (2019)

[11] Duekryul Sin, Liberal Arts Education, Geori Publishers, (2016) 